\title{
The Effects of the Recurrent Storms on Fof2 at Ouagadougou Station during Solar Cycles 21-22
}

\author{
Wambi Emmanuel Sawadogo1, Frédéric Ouattara1, Mahammat Nour Ali1,2 \\ ${ }^{1}$ Laboratoire de Recherche en Energétique et Météorologie de l'Espace (LAREME), Université Norbert Zongo (Anciennement \\ Université de Koudougou), Koudougou, Burkina Faso \\ ${ }^{2}$ Faculté des Sciences Exactes Appliquées (FSEA), Université de Ndjamena, Ndjamena, Tchad \\ Email: fojals@yahoo.fr
}

How to cite this paper: Sawadogo, W.E., Ouattara, F. and Ali, M.N. (2019) The Effects of the Recurrent Storms on Fof2 at Ouagadougou Station during Solar Cycles 21-22. International Journal of Geosciences, 10, 80-90.

https://doi.org/10.4236/ijg.2019.101006

Received: December 28, 2018

Accepted: January 28, 2019

Published: January 31, 2019

Copyright (C) 2019 by author(s) and Scientific Research Publishing Inc. This work is licensed under the Creative Commons Attribution International License (CC BY 4.0).

http://creativecommons.org/licenses/by/4.0/

Open Access

\begin{abstract}
The present paper deals with the effect of recurrent activity on the foF 2 diurnal variation at Ouagadougou station for solar cycles 21 and 22. The recurrent activity produces at daytime positive storm for all solar cycle phases. For all seasons, the recurrent activity causes positive storm during nighttime and has no effect during daytime. From this study, it emerges that a positive effect of the storm at this station may be explained by the thermospheric composition changes. Recurrent activity more occurs during the solar decreasing phase and during spring month. The storm strength shows solar cycle phase and seasonal dependence. The storm strength is the highest during the solar increasing phase and during summer months.
\end{abstract}

\section{Keywords}

Solar Wind High Speed Stream, Recurrent Activity, F2 Layer Critical Frequency, Solar Cycle Phases, Positive Storms

\section{Introduction}

An interaction between magnetized plasma propagating from the Sun and magnetic fields in the near-Earth space environment causes a global magnetic disturbance namely geomagnetic storms [1] which are due to geomagnetic activities.

Legrand and Simon [2] studied and classified the geomagnetic activity by using 1) the geomagnetic aa index carried out by Mayaud [3] [4], 2) the date of Sudden Storm Commencement (SSC) and 3) the correlation existing between the geomagnetic aa index and the solar wind speed established by Svalgaard [5]. Their four classes are: 1) quiet magnetic activity due to slow solar wind; 2) recurrent activity related to high speed solar wind streams coming from coronal 
holes; 3) shock events with SSC caused by Coronal Mass Ejections (CMEs) and 4) fluctuating activity due to the fluctuation of the solar neutral sheet. Richardson and Cane [6] also found the same number of the geomagnetic classes. But they named the fluctuating activity as the unclear activity which characterized the cases where the solar mechanisms cannot be clearly identified.

It is well known that the F layer depends on: 1) the sunspot cycle [7] [8]; 2) the Sun-Earth relative position at the origin of the seasonal variation and equinoctial maxima [9] [10]; 3) the solar wind speed [11] [12] and the shock activity [13].

The statistical study of the foF2 diurnal variation at Ouagadougou station (Lat: $12.4^{\circ} \mathrm{N}$; Long: $358.5^{\circ} \mathrm{E}$; dip: $1.43^{\circ}$ ) has been carried for the all geomagnetic activities [14]. Here, we focus our attention to a careful investigation on the F2 layer critical frequency (foF2) time variation at the same station when occurs the recurrent activity. This research is made after that of Gyébré et al. [15] which treated the different types of the shock activity impacts on foF2 time variation. The novelty of this study appears as it is a first paper where such statistical study is made. It is important to note that Rodríguez-Zuluaga et al. [16] also investigated the impact of this type of activity in the lower ionosphere but focus their attention on the role of the Interplanetary Magnetic Field (IMF) $B_{z}$ oscillation frequency. The interplanetary conditions and the magnetosphere state have been also visited to investigate recurrent events that produce recurrent geomagnetic storms or activities [17] [18]. In this work, the recurrent activity frequency is carried out during the solar cycles 21 and 22. The seasonal and the solar cycle phases dependence of the foF 2 diurnal variation under the recurrent activity are investigated.

Section 2 concerns materials and methods. Section 3 is devoted to results and discussions. Finally, we conclude by presenting the main results and highlighting the research perspectives.

\section{Materials and Methods}

The storm effect on ionosphere or ionospheric storm is associated with geomagnetic storm [19] [20]. It is well-known that geomagnetic storms show solar cycle phase and seasonal dependence [21] [22]. Therefore, we focus our intention on how the ionosphere F2 region of the African Equatorial Ionization Anomaly (EIA) sector reacts to the geomagnetic activity and principally reacts to the recurrent activity? We consider for our investigation, the solar cycle phases and the seasons dependences and analyse the profile with respect to the classification of Fayot and Vila [23].

\subsection{The Criteria for Determining the Solar Cycle Phases}

For the solar cycle phases determination, we use the following criteria [24]: 1) minimum phase: $\mathrm{Rz}<20$;2) increasing phase: $20 \leq \mathrm{Rz} \leq 100$ and $\mathrm{Rz}$ greater than the previous year's value; 3) maximum phase: $\mathrm{Rz}>100$ [for weak solar cycles (solar cycles with sunspot number maximum $\left(\mathrm{Rz}_{\max }\right)$ less than 100) the maxi- 
mum phase is obtained by considering $\mathrm{Rz}>0.8 * \mathrm{Rz}_{\max }$ ]; and 4) decreasing phase: $100 \geq \mathrm{Rz} \geq 20$ and $\mathrm{Rz}$ less than the previous year's value. In these previous inequations, $\mathrm{Rz}$ is the yearly average Zürich sunspot number.

\subsection{The Criteria for Determining the Seasons}

As many researchers [9] [10] [22] found seasonal dependence of F2 layer during geomagnetic storm, we examine the seasonal effects on the foF 2 time profiles under the recurrent activity. The seasons are classified as follows: winter (December, January and February), spring (March, April, May), summer (June, July, August) and autumn (September, October and November).

\subsection{The Method for Determining the Recurrent Activity}

The recurrent event is one of the three solar events (High speed solar wind coming from solar coronal hole, CMEs and fluctuating solar wind speed due to the fluctuation of the solar neutral sheet) that are able to provoke the geomagnetic storm (a phenomenology of a middle- and low-latitude-geomagnetic variations and quantified by the disturbance storm time (Dst) index [24]. For studying the geomagnetic storm, we use a pixel diagrams as done by Legrand and Simon [2]; Gyébré et al. [15] and the references with this method therein. A pixel diagram is carried out by selecting the geomagnetic data as a function of the solar activity as described by solar rotation (27 days) [2]. We do not describe the method used for getting a pixel diagram but suggest to the readers to detailed the works of Ouattara and Amory Mazaudier [14] and Gyébré et al. [15]. As in the present paper, only are interested the geomagnetic storms due to recurrent activity, we describe the method used to determine by means of a pixel diagram the geomagnetic storms generated by these activities. Keeping in mind that a pixel diagram (Figure 1) is an adopted colour codes that help to define a geomagnetic

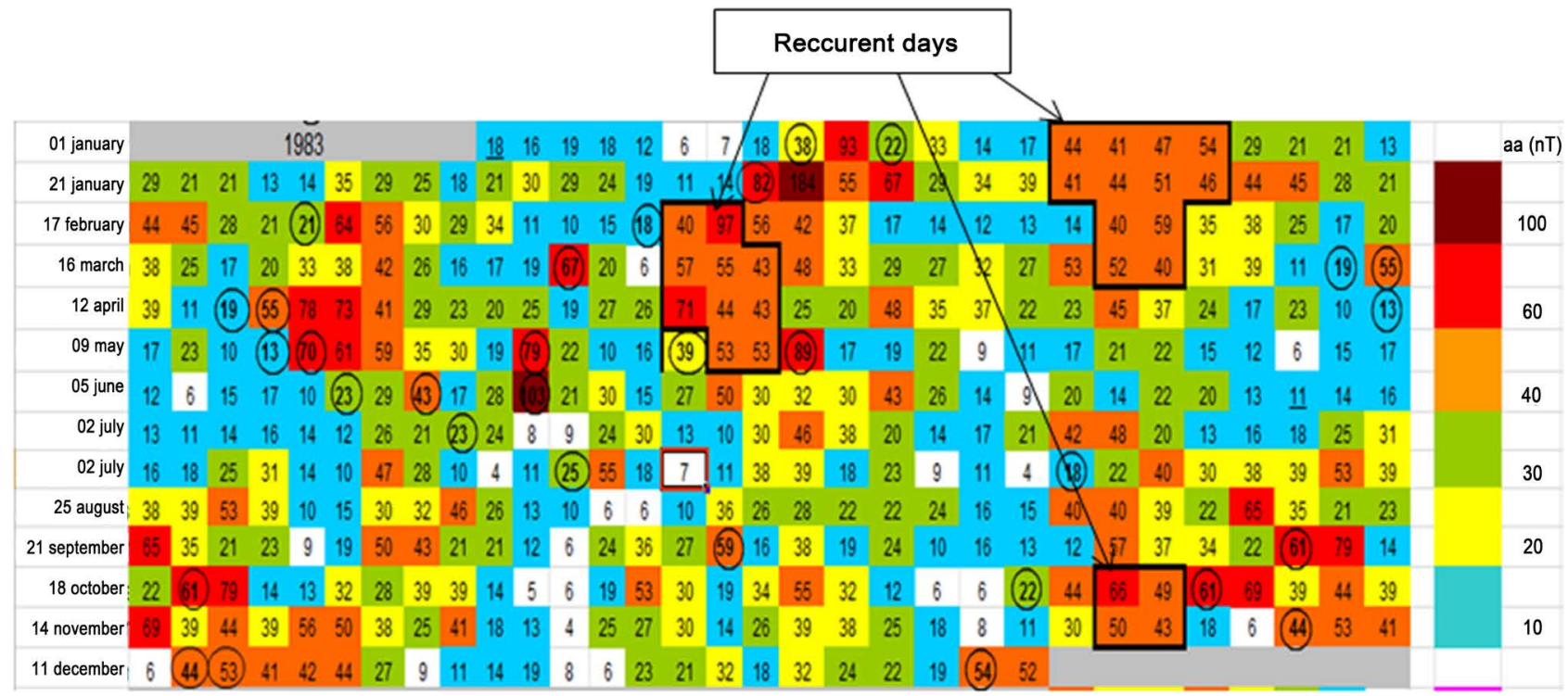

Figure 1. Recurrent activity days shown in the pixel diagram of year 1983. 
activity intensity. According to Legrand and Simon [2] and Ouattara and Amory Mazaudier [14] the recurrent activities are shown by several days (more than one) with merging or not orange, red and olive red colours during two or more Bartels' rotations. These colours correspond to a daily aa ( $\mathrm{Aa}$ ) values superior or equal to $40 \mathrm{nT}$. By using the pixel diagrams of the solar cycles 21 and 22, we have 173 recurrent days.

\subsection{The Method for Analyzing the Data}

Our data will be analysed into three ways: the first one is the electrodynamic point of view. In that case, the storm foF 2 profiles are analysed by comparing these profiles to those of a five typical foF2 time profiles in African EIA (Equatorial Ionization Anomaly) sector [the noon bite out profile or "B" profile expresses by two maximum peaks with a trough around midday in foF2 time profile, the morning peak profile or " $\mathrm{M}$ " profile shown by a presence of a peak in the foF 2 profile before midday, the dome profile or " $D$ " profile shown by a maximum peak around midday, the plateau profile or " $\mathrm{P}$ " profile shown by the constant values of foF 2 during two or more consecutive hours. In that case midday is included and the reverse profile or " $\mathrm{R}$ " profile where foF2 profile presents a peak after noon, [23]]. These profiles have been recorded to the equatorial ionosphere electric currents (equatorial electrojet and equatorial counter electrojet) strength, presence or absence, by reference to the electric current day-to-day time variation under the quiet time condition [25] [26].

The second one is the qualitative appreciation of the storm effects. Therefore, storm time foF 2 and quiet time foF 2 are plotted together and the deviation observed in storm foF2 with respect to quiet foF2 induces the storm impacts. The storm effects in foF2 time variation is appreciated by showing error bars (The error bars applied are carried out by means of $\sigma=\sqrt{V}$ where the variance $V$ is defined by $\frac{1}{N} \sum_{i=1}^{N}\left(x_{i}-\bar{x}\right)^{2}$ with $\bar{x}$ mean value and $N$ the total number of available data). With respect to error bars, the storm impacts are estimated in term of positive or negative storm. For their definitions see [19] [21] [22] and the all references therein.

The third one is the estimation of the storm strength. For the definition of the storm strength, we follow that of Vijaya Lekshmi et al. [22] by using the storm time deviation $\Delta \mathrm{foF} 2_{\text {hourly }}$. But here, $\Delta \mathrm{foF} 2_{\text {hourly }}$ is defined as follows: $\Delta \mathrm{foF} 2_{\text {hourly }}=\mathrm{foF} 2_{\text {storm hourly mean }}-\mathrm{foF} 2_{\text {quiet hourly mean }}$ where foF2 is critical frequency value of $\mathrm{F} 2$ layer. According to these authors the storm strength is the maximum positive value of $\Delta \mathrm{foF} 2_{\text {hourly }}$ for the positive storm and the maximum negative value of $\Delta \mathrm{foF} 2_{\text {hourly }}$ for the negative storm.

\section{Results and Discussions}

Figure 2 highlights the occurrence of the recurrent activity. The panel a concerns the solar cycle phases dependence and the panel $b$ that of the seasons. 

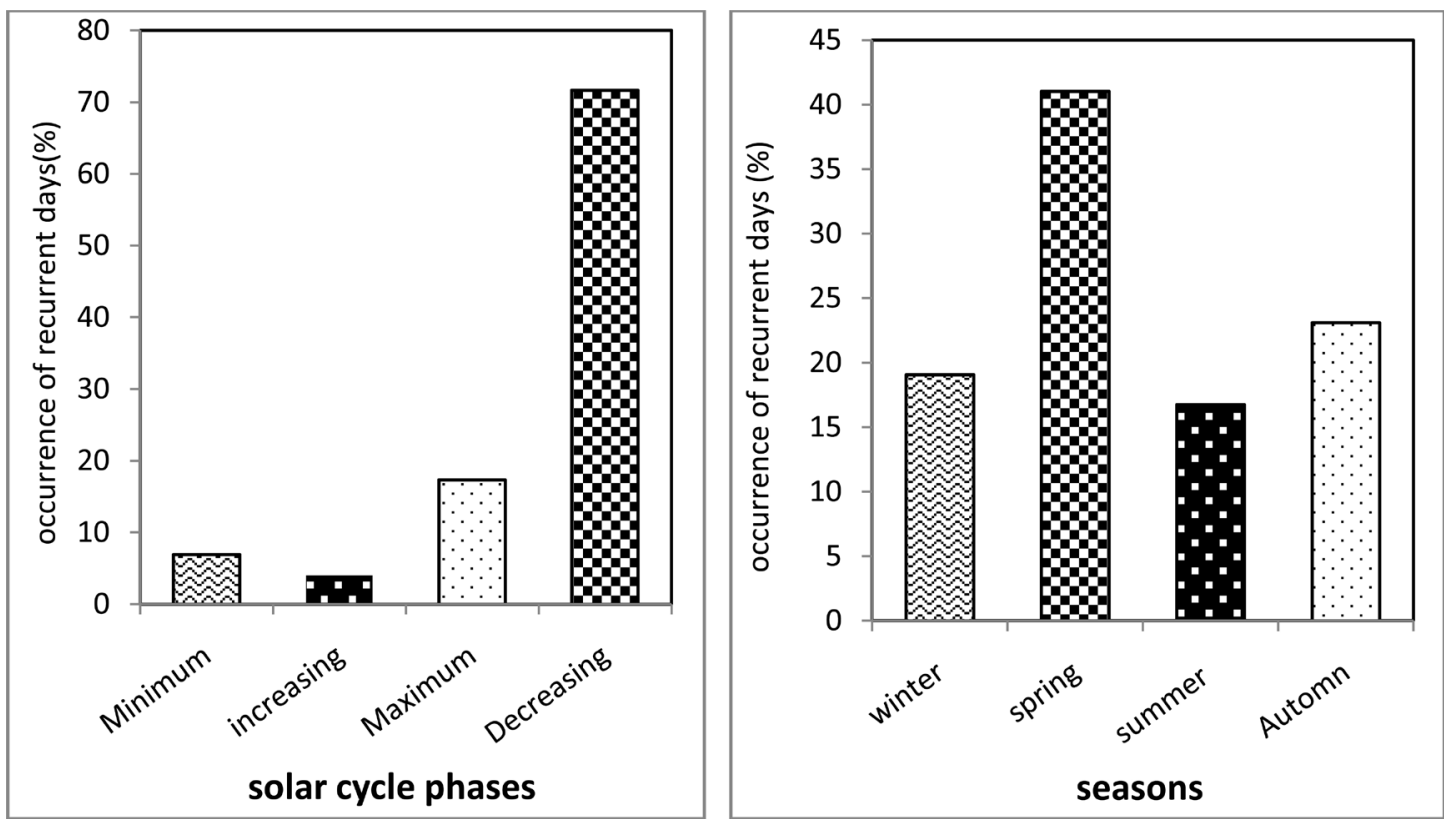

Figure 2. Recurrent activity occurrence variability during solar cycle phases (panel (a)) and seasons (panel (b)).

It can be seen from this figure that the recurrent activity more occurs during the solar decreasing phase with $71.67 \%$ of the global activity. This result has been previously noted by Zerbo et al. [27]. This situation can be explained by the fact that during the solar cycle decreasing phase, it emanates from the Sun coronal holes the high-speed solar wind streams responsible for the formation of the Corotating Interaction Regions (CIRs) by interacting with slow solar wind [18] and constitute the sources of the recurrent activity [2]. Also the number of solar active events such as solar flares, CMEs, etc., increase seriously during the decreasing phase of a cycle. The panel b shows that there is more recurrent activity during spring month with the occurrence of $41.04 \%$. This result expresses the equinoctial asymmetry of the seasonal occurrence of the recurrent activity.

Whatever the solar cycle phase it can be seen in Figure 3 that storm time profiles and quiet time profiles show the same behaviour during daytime. As here, the time profile shows a statistical time variation of foF 2 , the analysis of the smoothing steps in foF2 profiles is out of the scoop of this paper because it is not a case study. For analysing storm effects on foF2 time profile, we will focus our attention on ExB drifts because on one hand, foF2 time profile expresses the signature of the ExB [28] [29] and on the other hand, according to Fejer [30] during storm time, ExB drifts are affected by 1) the prompt penetration of magnetospheric convection electric fields; 2) the longer-lived dynamo electric fields [due to the disturbance neutral winds] and 3) storm related changes in ionospheric conductivity [30]. Buonsanto [31] shows that at daytime, during storm time, the prompt penetration of magnetospheric convection electric fields induces the upward vertical drift perturbation and the disturbance dynamo provokes the nearly opposite downward vertical drift perturbation. At daytime, based on the same type of foF2 profile (a noon bite out profile) observed during 

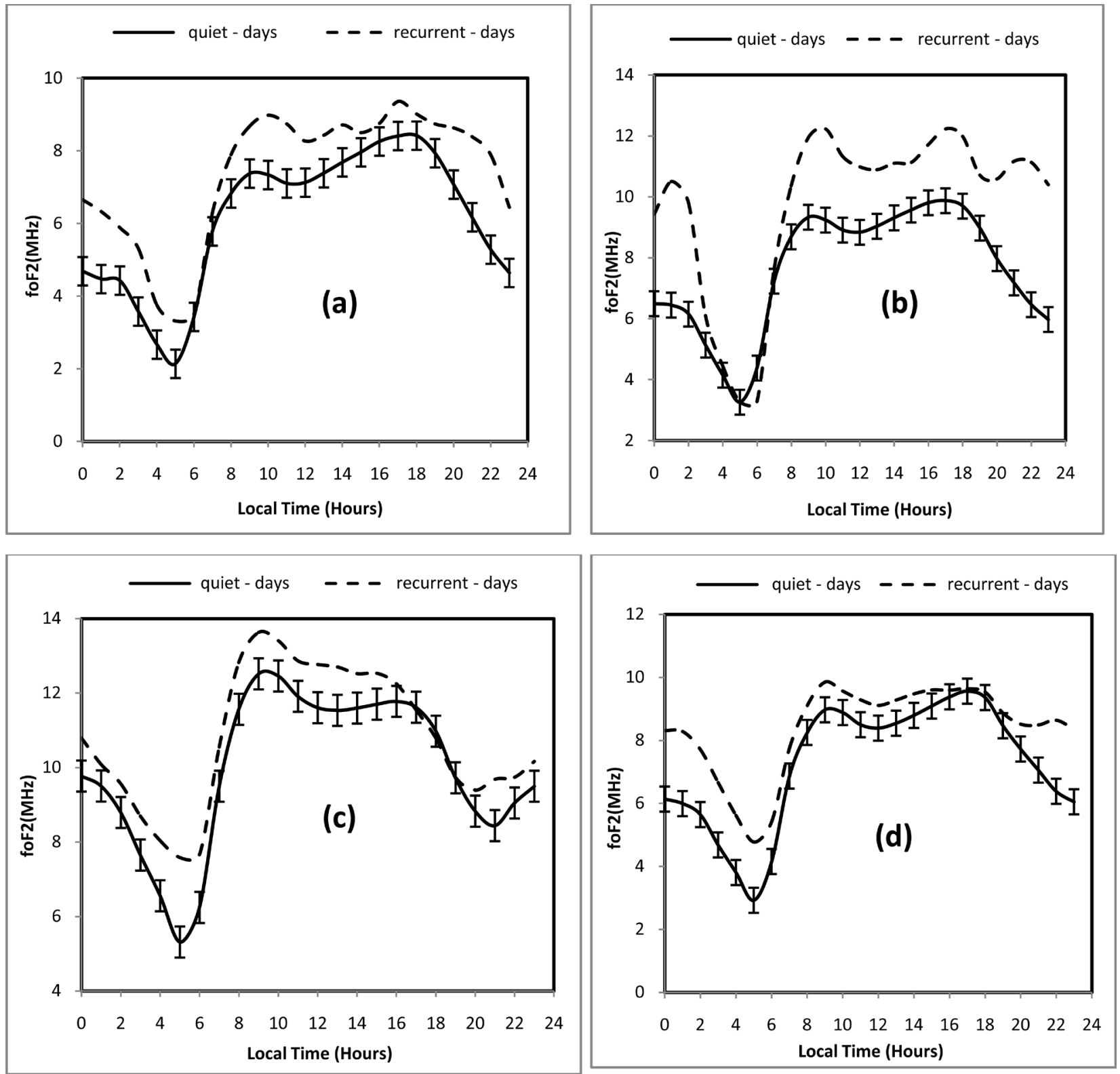

Figure 3. Solar cycle phase impacts on foF2 diurnal variation under quiet activity (solid curve) and recurrent activity (dashed curve). The panel (a)-(c) and (d) concerns the solar minimum, increasing maximum and decreasing phase, respectively.

quiet time and storm time, it appears that the above two mechanisms produce the opposite effects on foF2 time profile. Consequently, it seems to appear that the quiet time equatorial F2 region electrodynamic is not affected by the recurrent activity.

At nighttime during solar increasing and decreasing phases the storm profiles show a night time peak that expresses the signature of the reversal electric field in this latitude (Fejer, 1981 and Farley et al., 1986). It can be deduced from this result that recurrent activity induces the electrodynamic process that reverses the electric field at night time in this latitude during all solar cycle phases except for during the solar cycle decreasing phase. 
With respect the error bars shown in quiet time graph of each panel of Figure 3, we can assert that in general at daytime (0800 LT - 1600 LT), night time (2000 LT - $2400 \mathrm{LT}$ ) and before sunrise (0000 LT - $0300 \mathrm{LT}$ ) recurrent activity causes positive storm [storm time foF 2 values are superior to those of quiet time [32]] which is produced at this latitude by the thermospheric composition changes [19] [22]. According to Prölss and Jung [33] and Balan et al. [34] the mechanisms that produce a positive storm in low and mid latitudes are the recombination processes and the downward diffusion of the plasma by the mechanical effects of the storm-time equatorward neutral winds. It can be added to these above mechanisms the enhanced eastward prompt penetration electric fields [35] [36]. Vijaya Lekshmi et al. [22] pointed out that, on one hand, only neutral winds can produce the positive storm at low latitude and on the other hand, the winds and the eastward prompt penetration electric fields together are able to produce positive storms at low and mid-latitudes. A positive storm can be also explained by F2-layers uplifting which is due to EXB drift-induced [37]. By considering the same behaviour of foF 2 time profiles, we can assert at this station, the positive storm is produced by thermospheric composition changes. It can be noted that Gyébré et al. [15] by studying CMEs impact on F2-layer at Ouagadougou station, show that the storms due to CMEs also provoke positive storm. But the main difference between CMEs storms and recurrent storms impact is that CMEs storms modify F2-layer quiet time electrodynamic by producing positive and negative storms.

Figure 4 treats the diurnal variation of foF2 during all seasons under quiet and recurrent activities.

At daytime, except summer season where around noon foF2 storm time profile shows a peak which modifies the signature of EXB (it consists of producing a trough around midday in foF 2 quiet time profile), the recurrent activity does not modify the quiet time electrodynamic processes because both quiet time and disturbed time profiles show the same behavior. At night time, we observe in the storm time foF2 time profile a peak that expresses the signature of the reversal electric field at 2100 LT during winter (panel a), 2200 LT during autumn (panel d) and $2300 \mathrm{LT}$ during summer (panel b) and spring (panel c) of Figure 4, respectively.

By taking account the error bars, it can be retained that recurrent activity impact is observed at night time. In general, a positive storm is observed after 2200 LT and between $0000 \mathrm{LT}$ and $0200 \mathrm{LT}$. This impact is more pronounced during summer. This shows the equinoctial asymmetry of the storm action.

When we analyze Figure 3 and Figure 4, one can assert that:

For the solar cycle phase dependence (Figure 3), we have:

1) storm strength increasing phase $>$ storm strength $_{\text {minimum phase }}$;

2) storm strength minimum phase $>$ storm $_{\text {strength }}$ decreasing phase $_{\text {; }}$;

and

3) storm strength $\mathrm{decreasing} \mathrm{phase}>$ storm strength maximum phase $_{\text {e }}$. 
For the seasonal dependence (Figure 4), we can note that:
1) storm strength summer $>$ storm strength $_{\text {autumn }}$;
2) storm strength ${ }_{\text {autumn }}>$ storm strength $_{\text {spring }}$;

and

3) storm strength ${ }_{\text {spring }}>$ storm strength $_{\text {winter }}$.

The above solar cycle phase and seasonal dependence can be seen in Table 1.
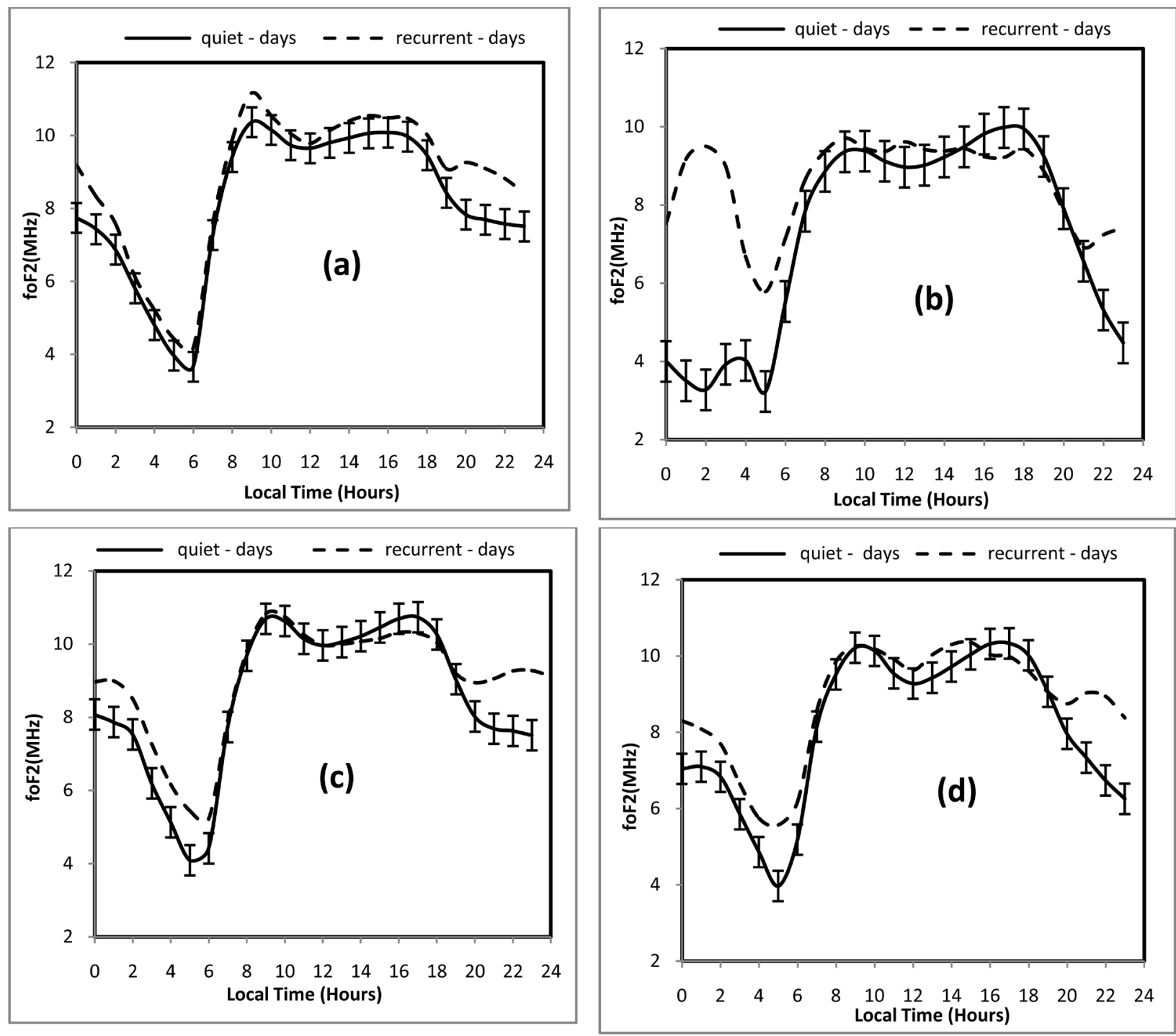

Figure 4. Seasonal impacts on foF2 diurnal variation under quiet activity (solid curve) and recurrent activity (dotted curve). The panel (a)-(c) and (d) concerns winter, summer, spring and autumn season, respectively.

Table 1. The storm strength solar cycle phases and seasonal dependence and seasonal.

\begin{tabular}{rrrrrr}
\hline (a) & The solar cycle phases dependence of the storm strength & Minimum & Increasing & Maximum & Decreasing \\
\cline { 2 - 6 } & $\max \Delta \mathrm{foF}_{\text {Hourly }}$ in $\mathrm{MHz}$ & 2.607 & 4.670 & 2.270 & 2.300 \\
\hline The seasonal dependence of the storm strength & Winter & Summer & Spring & Autumn \\
\cline { 2 - 6 } & $\operatorname{mafoF} 2_{\text {Hourly }}$ in $\mathrm{MHz}$ & 1.443 & 6.227 & 1.774 & 2.203 \\
\hline
\end{tabular}


Table 1(a) shows that for solar cycle dependence, the maximum strength occurs during the solar increasing phase and for seasonal dependence, the maximum storm strength occurs during summer season (see Table 1(b)).

\section{Conclusions}

The occurrence of the storm shows that recurrent storm mostly occurs during solar decreasing phase and during spring month.

The analysis of the foF 2 profile under recurrent and quiet activities at Ouagadougou station shows that, at daytime, the recurrent activity does not modify the quiet time electrodynamic of F2-layer at this station but induces the thermospheric composition changes. The recurrent activity produces a positive storm during each season and during each solar cycle phase. For solar cycle phases dependence, the present study points out that:

1) storm strength $_{\text {increasing phase }}>$ storm strength $_{\text {minimum phase }}$;

2) storm strength minimum phase $>$ storm strength $_{\text {maximum phase }}$; and

3) storm strength $h_{\text {maximum phase }}>$ storm strength decreasing phase $_{\text {; }}$;

For seasonal dependence, it can be retained that:

1) storm strength summer $_{\text {s }}>$ storm $_{\text {strength }}$ autumn ;

2) storm strength ${ }_{\text {autumn }}>$ storm $_{\text {strength }}$ spring ;

and

3) storm strength $\mathrm{spring}>$ storm strength $\mathrm{winter}_{\text {. }}$.

\section{Conflicts of Interest}

The authors declare no conflicts of interest regarding the publication of this paper.

\section{References}

[1] Tommaso, A., Mirko, P., Antonio, V., Paula De, M., Fabio, L., Vincenzo, C. and Leonardo, P. (2016) Identification of the Different Magnetic Field Contributions during a Geomagnetic Storm in Magnetospheric and Ground Observations. Annales Geophysicae, 34, 1069-1084. https://doi.org/10.5194/angeo-34-1069-2016

[2] Legrand, J.P. and Simon, P.A. (1989) Solar Cycle and Geomagnetic Activity: A Review for Geophysicists, Part I. The Contributions to Geomagnetic Activity of Shock Waves and of the Solar Wind. Annales Geophysicae, 7, 565-578.

[3] Mayaud, P.N. (1971) A Measurement of Planetary Magnetic Activity Based on Two Antipodal Observatories. Annales Geophysicae, 27, 67-71.

[4] Mayaud, P.N. (1972) The aa Indices: A 100-Year Series, Characterizing the Magnetic Activity. Journal of Geophysical Research, 77, 6870-6874.

https://doi.org/10.1029/JA077i034p06870

[5] Svalgaard, L. (1977) Geomagnetic Activity: Dependence on Solar Wind Parameters. In: Zirker, J.B., Ed., Coronal Holes and High-Speed Wind Streams. Colorado Association University Press, Boulder, 371-432.

[6] Richardson, I.G. and Cane, H.V. (2002) Sources of Geomagnetic Activity during 
Nearly Three Solar Cycles (1972-2000). Journal of Geophysical Research, 107, 1187. https://doi.org/10.1029/2001JA000504

[7] Rishbeth, H. and Mendillo, M. (2001) Pattern of F2-Layer Variability. Journal of Atmospheric and Solar-Terrestrial Physics, 63, 1661-1680.

https://doi.org/10.1016/S1364-6826(01)00036-0

[8] Pancheva, D., Mitchell, N., Clark, R.R., Drobjeva, J. and Lastovicka, J. (2002) Variability in the Maximum Height of the Ionospheric F2-Layer over Millstone (September 1998-March 2000); Influence from Below and Above. Annals of Geophysics, 20, 1807-1819. https://doi.org/10.5194/angeo-20-1807-2002

[9] Rishbeth, H., Muller-Wodarg, I.C.F., Zou, L., Fuller-Rowell, T.J., Millward, G.H., Moffett, R.J., Idenden, D.W. and Aylward, A.D. (2000) Annual and Semiannual Variations in the Ionospheric F2-Layer: II. Physical Discussion. Annales Geophysicae, 18, 945-956. https://doi.org/10.1007/s00585-000-0945-6

[10] Zou, L., Rishbeth, H., Muller-Wodarg, I.C.F., Aylward, A.D., Millward, G.H., Fuller-Rowell, T.J., Idenden, D.W. and Moffett, R.J. (2000) Annual and Semiannual Variations in the Ionospheric F2-Layer I. Modelling. Annals of Geophysics, 18, 927-944. https://doi.org/10.1007/s00585-000-0927-8

[11] Lotko, W. (1989) Report of the Working Group on Ionospheric Signatures. GEM Report on the Workshop on Magnetospheric and Boundary Layer Physics, La Jolla, CA.

[12] Simon, P.A. and Legrand, J.P. (1989) Solar Cycle and Geo-Magnetic Activity: A Review for Geophysicists Part II. The Solar Sources of Geomagnetic Activity and Their Links with Sunspot Cycle Activity. Annales Geophysicae, 7, 579-594.

[13] Ouattara, F. and Zerbo, J.L. (2011) Ouagadougou Station F2 Layer Parameters Yearly and Seasonal Variations during Severe Geomagnetic Storms Generated by CMEs and Fluctuating Wind Streams. International Journal of Physical Sciences, 6 , 4854-4860.

[14] Ouattara, F., Amory Mazaudier, C., Vila, P., Fleury, R. and Lassudrie Duchesne, P. (2009) West African Equatorial Ionospheric Parameters Climatology Based on Ouagadougou Station Ionosonde Data from June 1966 to February 1998. Annales Geophysicae, 27, 2503-2514. https://doi.org/10.5194/angeo-27-2503-2009

[15] Gyebré, A.M.F., Gnabahou, D.A. and Ouattara, F. (2018) The Geomagnetic Effects of Solar Activity as Measured at Ouagadougou Station. International Journal of Astronomy and Astrophysics, 8, 178-190. https://doi.org/10.4236/ijaa.2018.82013

[16] Rodriguez-Zuluaga, L., Radicella, S.M., Nava, B., Amory-Mazaudier, C., Mora-Paez, H. and Alazo-Cuartas, K. (2016) Distinct Responses of the Low Latitude Ionosphere to CME and HSSWS: The Role of the IMF $\mathrm{B}_{\mathrm{z}}$ Oscillation Frequency. Journal of Geophysical Research, 121, 11528-11548. https://doi.org/10.1002/2016JA022539

[17] Tsurutani, B.T. and Gonzale, W.D. (1987) The Cause of High Intensity Long-Duration Continuous AE Activity (HILDCAAs): Interplanetary Alfvén Wave Trains. Planetary and Space Science, 35, 405-412. https://doi.org/10.1016/0032-0633(87)90097-3

[18] Guarnieri, L.F., Tsurutani, T.B., Gonzalez, D.W., Gonzalez, L.C.A., Grande, M., Soraas, F. and Echer, E. (2006) ICME and CIR Storms with Particular Emphases on HILDCAA Events. ILWS Workshop, GOA, 19-20 February, 1-8.

[19] Fuller-Rowell, T.-J., Codrescu, M.V., Moffett, R.J. and Quegan, S. (1994) Response of the Thermosphere and Ionosphere to Geomagnetic Storms. Journal of Geophysical Research, 99, 3893-3914. https://doi.org/10.1029/93JA02015

[20] Sahai, Y., Shiokawa, K., Otsuka, Y., Ihara, C., Ogawa, T., Igarashi, K., Miyazaki, S. and Saito, A. (2001) Imaging Observations of Midlatitude Ionospheric Disturbances 
during the Geomagnetic Storm of February 12, 2000. Journal of Geophysical Research, 106, 24481-24492.

[21] Danilov, A.D. (2013) Ionospheric F-Region Response to Geomagnetic Disturbances. Advances in Space Research, 52, 343-366. https://doi.org/10.1016/j.asr.2013.04.019

[22] Vijaya Lekshmi, D., Balan, N., Tulasi Ram, S. and Liu, J.Y. (2011) Statistics of Geomagnetic Storms and Ionospheric Storms at Low and Mid-Latitudes in Two Solar Cycles. Journal of Geophysical Research, 116, A11328.

[23] Faynot, J.M. and Vila, P. (1979) F-Region at the Magnetic Equator. Annales Geophysicae, 35, 1-9.

[24] Gnabahou, D.A. and Ouattara, F. (2012) Ionosphere Variability from 1957 to 1981 at Djibouti Station. European Journal of Scientific Research, 73, 382-390.

[25] Vassal, J.A. (1982) La variation du champ magnétique et ses relations avec I'électrojet équatorial au Sénégal Oriental. Annales Geophysicae, 3, 347-355.

[26] Vassal, J.A. (1982) Electrojet, contre électrojet et région F à Sarh (Tchad). Géophysique. ORSTOM, Paris.

[27] Zerbo, J.L., Ouattara, F., Mazaudier, C.A. and Legrand, J.P. (2013) Solar Activity, Solar Wind and Geomagnetic Signatures. Atmospheric and Sciences, 3, 610-617.

[28] Fejer, B.G. (1981) The Equatorial Ionospheric Electric Fields. A Review. Journal of Atmospheric and Terrestrial Physics, 43, 377-386. https://doi.org/10.1016/0021-9169(81)90101-X

[29] Farley, D.T., Bonell, E., Fejer, B.G. and Larsen, M.F. (1986) The Prereversal Enhancement of the Zonal Electric Field in the Equatorial Ionosphere. Journal of Geophysical Research, 91, 13723-13728. https://doi.org/10.1029/JA091iA12p13723

[30] Fejer, B.G. (1997) The Electrodynamics of the Low-Latitude Ionosphere: Recent Results and Future Challenges. Journal of Atmospheric Solar-Terrestrial Physics, 59, 1465-1482. https://doi.org/10.1016/S1364-6826(96)00149-6

[31] Buonsanto, M.J. (1999) Ionospheric Storms: A Review. Space Science Reviews, 88, 563-601. https://doi.org/10.1023/A:1005107532631

[32] Jin, S., Rui, H. and Jin, K. (2017) Positive and Negative Ionospheric Responses to the March 2015 Geomagnetic Storm from BDS Observations. Journal of Geodesy, 91, 613-626.

[33] Prölss, G.W. and Jung, M.J. (1978) Travelling Atmospheric Disturbances as a Possible Explanation for Daytime Positive Storm Effects of Moderate Duration at Middle Latitudes. Journal of Atmospheric and Terrestrial Physics, 40, 1351-1354. https://doi.org/10.1016/0021-9169(78)90088-0

[34] Balan, N., Liu, J.Y., Otsuka, Y., Liu, H. and Lühr, H. (2011) New Aspects of Thermospheric and Atmospheric Storms Revealed by CHAMP. Journal of Geophysical Research, 116, A07305. https://doi.org/10.1029/2010JA016399

[35] Kelley, M.C., Vlasov, M.N., Foster, J.C. and Coster, A.J. (2004) A Quantitative Explanation for the Phenomenon Known as Storm-Enhanced Density. Geophysical Research Letters, 31, L19809. https://doi.org/10.1029/2004GL020875

[36] Mannucci, A.J., Tsurutani, B.T., Lijima, B.A., Komjathy, A., Salto, A., Gonzalez, W.D., Guarnieri, F.L., Kozyra, J.U. and Skoug, R. (2005) Dayside Global Ionospheric Response to the Major Interplanetary Events of October, 29-30, "Halloween Storms". Geophysical Research Letters, 32, L12S02.

[37] Danilov, A.D. (2001) F2-Region Response to Geomagnetic Disturbances. Journal of Atmospheric and Solar-Terrestrial Physics, 63, 441-449. https://doi.org/10.1016/S1364-6826(00)00175-9 